\title{
Research on Higher Mathematics Teaching Reform Based on the Cultivation of Applied Talents
}

\author{
Xiaobo Liu \\ School of information engineering, Nanjing Xiaozhuang University, Nanjing, China \\ 4487758@qq.com
}

Keywords: Applied Talents, Higher Mathematics, Teaching Reform.

\begin{abstract}
According to the orientation of cultivating applied talents of colleges and universities, this paper discussed the reform on teaching target, content, method and appraisal of higher mathematics course based on the analysis on the necessity of higher mathematics course reform in colleges and universities.
\end{abstract}

\section{The Necessity of Reforming Higher Mathematics Teaching In Colleges And Universities Which Cultivated Applied Talents}

The fundamental purpose of the education and teaching in colleges and universities is to improve the quality of personnel training. The core of improving the quality of personnel training is reforming the personnel training mode on the premise of following the law of education to make the talent training scheme and training methods coordinate with talents cultivation objectives and specifications better, and meet the needs of the society better. It is to cultivate innovative talents of science and technology and higher technology applied talents for territorial economy, construction and development.

Applied talent was a specialized talent type which could apply professional knowledge and skills in social practice. Applied talents training mode is taking ability as the center, and taking cultivating technology applied talents as the objective. The required "ability" is not only the post ability, but also the professional post group ability, is not only a professional ability, but also a comprehensive ability, is not only the employment ability, but also a certain entrepreneurial ability, is not only the regeneration ability, but also creative skills. The required "technology" is the technology which have complex and comprehensive characteristics on the basis of certain scientific theory, and beyond the general skills, and it includes not only experience technology, but also the theory of technology.

Higher mathematics is an important basic theory course in colleges and universities, it has unique roles of cultivating students' abstract generalization ability, logical thinking ability, and operation ability what other courses couldn't replace. Chinese higher education has entered the stage of popularization. The student's mathematical foundation was relatively poor in undergraduate colleges and universities, and their average admission abilities declined. The decline included learning basis, ability and consciousness. Higher mathematics course only actively adapts to the new situation of popularization of higher education, and reform the teaching means and methods, the teaching quality and effect could be improved fundamentally. In terms of content, it was not the more or the deeper you learn, the better you were, but took application as the purpose, and focus on cultivating students' ability of applying higher mathematics to solve practical problems, and on the students' ability of grasping the math thought, method and spiritual.

At present, the teaching status of higher mathematics in Chinese universities is worrying. In terms of recognition, many teachers are not even familiar with the connection between higher mathematics with students' subsequent professional courses. Most of the teachers graduated from the major of mathematics and have profound mathematical theoretical knowledge, so they can speak theory with ease, but sometimes they do not know where to start when they talk about application. In terms of students, students have little contact with application due to the long-term orientation of textbook 
content and examination, and they are not clear about the purpose of learning higher mathematics. They cannot feel the influence and effect of math class on professional courses, and cannot see its practical value.

In terms of content, it has the phenomenon of focusing on theory and rigorous logical derivation, and neglecting application, introducing mathematical concept from practical problems and background analysis of the concept on the used textbooks, there is very limited space for applications in teaching. Moreover, teachers lay particular stress on knowledge teaching, ignore the combination of teaching content with professional learning and practical problems and neglect the cultivation of students' mathematical ability and consciousness, which is not suitable for the school-running orientation of cultivating applied talents in newly-built local universities to a large extent.

In terms of method, teachers have used injection teaching method which caused the students' laziness in thinking. Practical teaching is weak, and students learn more but use less. Mathematical experiment and modeling are the weakest link in the teaching of higher mathematics in most universities. It has new and higher requirements for personnel of mathematics knowledge structure, ability and quality in various fields of science and technology of current and future society, therefore, mathematics education thought should conform to the need of modern people and make corresponding adjustment, teachers not only teach students mathematical thought and method in higher mathematics, but also guide students to know how apply these knowledge, combine mathematics method with the actual problem organically, and build a mathematical model from the complex phenomenon?

\section{Reform Path of Higher Mathematics Teaching Based On The Perspective Of Application-Oriented Talent Training}

In order to adapt to the new situation of higher education popularization and meet the practical demand of local economic and social development for applied talents, it is necessary to reform the teaching content, requirements and methods of higher mathematics courses.

\subsection{The target.}

Local universities should follow the practical undergraduate teaching philosophy of "solid foundation, suitable caliber, heavy application and strong ability", and reform the course teaching objectives, teaching requirements and teaching outline.

A. Establishing the teaching objectives in the three dimensions of knowledge and skills, process and methods, emotional attitude and values of higher mathematics courses. B. Changing the traditional disciplines as the standard, the system which emphasize theoretical knowledge and complete academic course requirements too much, according to the requirements of applied talents training and higher mathematics teaching requirements, the key is to understand the basic concepts, to grasp the method of mathematics, highlight the mathematical thought and strengthen the cultivation of students' numerical calculation and data processing ability, it asked students could solve practical problems with mathematical calculation software. C. Changing the current status of teaching students at the two levels of engineering and liberal arts. According to the requirements of the major on the contents of higher mathematics, the course syllabus that is suitable for the training objectives of different majors should be formulated in different categories.

\subsection{The content.}

In order to achieve the established objectives, it should be in accordance with the requirements of applied talents training goal, break the traditional architecture of curriculum system in certain cases of settled total teaching hour, and establish the curriculum framework content which take ability training as the standard in accordance with the teaching ideas of "one purpose, two transitions, three levels, four relations". "One purpose" is to form an overall structure of knowledge according to the training needs of applied talents, with problems as the introduction, mathematical thinking and methods as the main line, and applying theories to solve problems. The "two transitions" are a shift from a systematic curriculum orientation to an application orientation that emphasizes professional needs, and from a 
theory orientation to an application orientation. "Three levels" is to divide the whole teaching content into three levels: basic, applied and deepened. The "four relations" is the overall design in the course system according to the law of cultivating applied talents, dealing with the relations between concrete and abstract, whole and part, knowledge and method, result and process.

\subsection{The method.}

Interactive. Building the classroom culture of communication, truly taking the classroom as a process of dialogue and interaction, and realizing the new teaching mode from "monologue" to "dialogue".

Interestingness. Interest is the best teacher. However, from middle school to university, students generally lack interest in mathematics [1]. The content of higher mathematics application teaching is broad, the teacher can't reach every aspect of a matter in the teaching, and should be "dominated by the teacher, and take the student as the main body", adopt flexible and varied, lively and interesting teaching methods in teaching, so as to fully mobilize students' autonomy, stimulate students' interest in learning, for example, the establishment of extra-curricular interest groups, and opening discussion class could make students more exposure to some examples of applications of higher mathematics, and make students more in-depth and comprehensive understanding the application method of higher mathematics and the development direction of it.

Visualization. Klein believed that mathematical understanding was obtained by intuitive methods, while logical statements were at best an auxiliary tool for learning. In the teaching, we should combine the teaching media according to the content of the textbook to create a novel teaching design and make abstract problems intuitive. For example, when explaining the concept of linear space, students can understand the concept of linear space by understanding the familiar three-dimensional vector space, which is convenient for students to understand and remember.

Simplification. Teachers should create teaching situations, properly transform abstract problems into familiar problems, handle the most complex problems in the simplest way, and explain the most profound theories in the simplest language. There are many fundamental theorems and propositions in higher mathematics. To affirm a proposition requires strict proof, and to negate an example requires only a counter-example. As we all know, if the function $\mathrm{f}(\mathrm{x})$ is differentiable in $x_{0}$, it must be continuous at the point $x_{0}$, but the opposite may not be true. For example, the function $f(x)=|x|$ is continuous and nondifferentiable at the point $\mathrm{x}=0$.

Systematization. Mathematical knowledge is an organic entirety, there are many internal relations among its parts. In teaching, we should pay attention to use the methods of "induction, analogy, association, and thought" and so on, so that students focus on the entirety, and achieve mastery through a comprehensive study of the subject.

Life style. The teacher must change the "absolutely rigorous" mathematical concept and try every possible way to create an atmosphere. With the help of image metaphor, the teacher can relate to the reality of life, show the charm of mathematics, highlight the mathematical thinking and methods, and guide the students to experience and appreciate mathematics.

The core calculus of higher mathematics comes from natural science, engineering technology and daily life, which is the abstraction and sublimation of practical problems. Therefore, in the teaching process of the concept of higher mathematics, the concept can only be elaborated precisely by combining with the specific practical background of life. For example, when introducing the concept of double integral, it can be explained through the physical background, and it can be known from physics that the value of the known surface density can be used to calculate the mass of the uniform plane sheet. However, if the surface density at each point of the planar slice is devariable, the quality of the slice shall be obtained by means of segmentation, approximation, summation and approximation. Through this method of finding the quality of non-uniform planar slices, the concept of double integral could be introduced step by step, so as to deepen the understanding of the concept, and then repeat the idea of double integral through the geometric background. For example, when talking about the derivative concept, we can discuss the speed problem, and then introduce the derivative concept after repeatedly elaborating the tangent problem, temperature change rate problem 
and line density problem. In this way, students not only understand the derivative concept, but also know that the mathematical concept comes from the actual problem. When talking about derivative and differential, we can draw the geometric meaning of them in a plane rectangular coordinate system, one is the tangent, the other is the increment of the tangent, so that students can have an intuitive understanding of the abstract concept, and improve students' interest in learning higher mathematics.

Abstract. The abstract content is intuitively described through individual specific or local concrete examples or experiences. On this basis, abstract results are summarized from the concrete to cultivate students' abstract ability. At the same time, abstract concepts, conclusions and laws are integrated into a rational and concrete way of thinking to cultivate students' ability to use theories to solve specific problems.

Practicality. In the teaching process of higher mathematics, cultivating students' awareness of "using mathematics" is one of its main tasks [2]. The choice of application of higher mathematics teaching content should be scientific, not only consider the application of reality, but also need to be able to predict the future, through this part of the teaching, teachers should enable students to master how to combine mathematics knowledge with practical problems organically, make students realize the importance and necessity of learning higher mathematics application, enhance students pay attention to cultivate the ability and consciousness of solving actual problem with mathematics method, and enhance learning initiative and creativity. The viewpoint of mathematics application should be the main idea of higher mathematics teaching and the basic starting point of organizing higher mathematics teaching. When talking about the limit of sequence, the growth model can be introduced. When we talk about differential equations, we can talk about population growth and missile tracking. By learning from demonstration examples and exercises, it not only let the students as much as possible to see application examples of higher mathematics knowledge points, and deepened students' understanding and grasping for the basic content of higher mathematics, realize understand the thought of establishing mathematical model, cultivate the students' ability to analyze and solve practical problems preliminarily, stimulate the students' learning interest and enthusiasm, improve the teaching effect, and inject vitality to teaching.

Process. In the higher mathematics teaching, teachers should focus on process, on revealing the process and rules of knowledge formation, which include finding success from the failure, helping students to form a positive learning attitude and scientific exploring spirit, letting the students get emotional experience, form values, cultivate students' creative ability and innovative spirit, and promote the all-round development of students.

Epoch-making. The development of many subjects is more and more important for mathematics. In order to meet the requirements of the times, teachers must change their old ideas and concepts that only focus on theory education in the teaching of higher mathematics. Under the new situation, teachers should be not only clear about every mathematical concept, formula and theorem proving, but also understand and research some aspects on the application of the mathematics ulteriorly, for example, a mathematics teacher teach economics class could read economic books appropriately, learn which aspects of economic profession have used higher mathematics knowledge, and how to apply these knowledge, look far ahead and aim high, and have a definite object in view in the teaching.

\subsection{Evaluation.}

Teaching evaluation is an important part of teaching, is the important way of checking teachers' teaching effect and students' learning effect. Through the evaluation, teachers can test the teaching effect of higher mathematics, in order to adjust the next phase of the teaching plan; Students can also learn to master knowledge and skills, and improve their learning methods. Higher mathematics knowledge is more, a one-time final exam is often not more objectively reflect the teachers' teaching, so it is necessary to combine the final one-time examination with regular assessment, course assignment, and open-book examination, in order to make up for the inadequacy of a single test, to avoid the defects of a single test. Teacher should also increase the proportion of usual performance to guide students apply mathematics, and promote students' active learning. The usual performance 
include classroom practice, learning experience, extracurricular reading notes, teaching papers, regular assignments, class attendance, classroom questioning, consulting information, analyzing information, and application example, etc. It can not only broaden students' knowledge, inspire students' interest in learning mathematics, but also can cultivate students' ability of solving practical problems by using mathematical knowledge. The diversified methods of assessment improve the students' enthusiasm to participate fully in the teaching link, fundamentally change the disadvantages of taking written examination as the only means of assessment at present.

\section{Acknowledgement}

The teaching project of Nanjing Xiaozhuang University: Research on "university mathematics" practical teaching under the goal of training applied talents stage result. The faculty teaching development program of Nanjing Xiaozhuang University: Research on practice strategy of promoting the students' autonomic learning___taking higher mathematics teaching as an example.

\section{References}

[1] Liu Xinghua, On analysis of the questionnaire which is about Mathematicians' discussion on mathematics learning, Journal of Mathematics Education, vol. 1, 2003.

[2] Liu Li, Liu Aiguo, Thinking and exploration of cultivating students' consciousness of applying mathematics, College Mathematics, p. 21, vol.6, 2004. 